\title{
Capsaicin mediates caspases activation and induces apoptosis through P38 and JNK MAPK pathways in human renal carcinoma
}

Tao Liu ${ }^{1 \dagger}$, Gang Wang ${ }^{2 \dagger}$, Huangheng Tao ${ }^{3 \dagger}$, Zhonghua Yang ${ }^{2}$, Yongzhi Wang ${ }^{2}$, Zhe Meng ${ }^{2}$, Rui Cao ${ }^{2}$, Yu Xiao ${ }^{2}$, Xinghuan Wang ${ }^{2^{*}}$ and Jiajie Zhou ${ }^{1^{*}}$

\begin{abstract}
Background: Renal cell carcinoma (RCC) is one of the tumors most refractory to chemotherapy to date. Therefore, novel therapeutic agents are urgently needed for this disease. Capsaicin (CPS), a natural active ingredient of green and red peppers, and a ligand of transient receptor potential vanilloid type 1 (TRPV1), has been showed potential in suppression of tumorigenesis of several cancers. Nonetheless, the anti-cancer activity of CPS has never been studied in human RCC.

Methods: CCK8 analysis, LDH release activity and ROS generation analysis, flow cytometry analysis, and nuclear staining test were performed to test the influence of CPS in cultured cells in vitro, meanwhile western blot was done to uncover the precise molecular mechanisms. 786-O renal cancer xenografts were builded to investigate the antitumor activity of CPS in vivo.

Results: We found treatment of CPS reduced proliferation of renal carcinoma cells, which could be attenuated by TRPV1 representative antagonist capsazepine (CPZ). CPS induced obvious apoptosis in renal carcinoma cells. These events were associated with substantial up-regulation of pro-apoptotic genes including c-myc, FADD, Bax and cleaved-caspase-3, -8, and -9, while down-regulation of anti-apoptotic gene Bcl2. Besides, CPS-treatment activated P38 and JNK MAPK pathways, yet P38 and JNK inhibitors afforded protection against CPS-induced apoptosis by abolishing activation of caspase-3, -8, and -9. Furthermore, CPS significantly slowed the growth of 786-O renal cancer xenografts in vivo.
\end{abstract}

Conclusions: Such results reveal that CPS is an efficient and potential drug for management of human RCC.

Keywords: Capsaicin, Renal cell carcinoma, TRPV1, Caspases, Apoptosis, MAPK

\section{Background}

As the most common type of kidney cancer, renal cell carcinoma (RCC) is a worldwide public concern. Human RCC accounts for 2 to $3 \%$ of all cancers, and approximately $90 \%$ of kidney cancer, with an increasing incidence of diagnosis (representing 200,000 patients diagnosed per year worldwide) [1]. Unluckily, one third of the patients

\footnotetext{
*Correspondence: wangxinghuan@whu.edu.cn; zhoujiajiejingzhou@126.com ${ }^{\dagger}$ Equal contributors

²Department of Urology, Zhongnan Hospital of Wuhan University, Center for Medical Science Research, Zhongnan Hospital of Wuhan University, Wuhan 430071, China

'Department of Urology, Jingzhou Central Hospital, the Second Clinical

Medical College, Yangtze University, Jingzhou 434020, China

Full list of author information is available at the end of the article
}

with RCC are diagnosed with metastatic or advanced diseases in a late stage, with a horribly high mortality rate counting approximately 100,000 deaths annually [1]. In the last decade, immunotherapy has become the major therapeutic option, yet with a low response rate (less than 20 \%) [2]. Recently, molecular targeted small-molecule anti-cancer drugs such as sunitinib and sorafenib have shown a much better response in mRCC, however this therapy has been found to be associated with the development of renal impairment and the overall survival is still not satisfied [3]. Thus, novel anti-cancer agents for RCC (especially for mRCC) with high efficiency and safety are urgently needed. 
Ion channels have a controversial role in cell proliferation and numerous studies have strongly confirmed that ion channels participated in nearly all basic cellular behaviors, including proliferation, differentiation, and apoptosis [4]. Transient receptor potential vanilloid type 1 (TRPV1) is a nonselective, ligand-gated cationic channel which can be regulated by thermal, mechanical and chemical stimuli such as CPS [5]. Primarily found in smalldiameter nociceptive neurons, TRPV1 was subsequently found to be expressed in non-neuronal tissues such as bladder, cornea and renal [6-8]. Besides, TRPV1 was found to play important physiologic and pathological roles in renal, and its activation would make much improvement in acute and chronic renal diseases $[9,10]$.

Phytochemicals, particularly those included in the human diet, are ideal candidates for antitumorigenesis, antimutagenesis, or chemotherapy. CPS is a major pungent ingredient in red and green peppers which are widely used as spice [11]. CPS can activate TRPV1 channel specifically, inducing a temperary transient $\mathrm{Ca}^{2+}$ flux and an increase in cytosolic calcium concentration [12]. Emerging evidence shows that CPS has the potential to selectively suppress the growth of various human tumor cells in culture, including gastric [13] and prostate cancer cells [14]. What's more, CPS has also exhibited anti-cancer effects in animal models, suppressing carcinogenesis of the colon [15], and lung [16]. However, the effects of CPS on renal cancer have never been investigated before. In this paper, the human renal carcinoma cell lines were selected to investigate whether CPS has anti-cancer effects on RCC and further clarify its mechanisms.

\section{Methods}

\section{Cell culture}

The human renal cell carcinoma 786-O, ACHN, Caki-1 cells (American Type Culture Collection, Manassas, VA) were cultured in RPMI 1640 medium containing $10 \%$ fetal bovine serum (FBS, Gibco), $100 \mathrm{U} / \mathrm{ml}$ penicillin-G sodium and $100 \mu \mathrm{g} / \mathrm{ml}$ streptomycin sulfate at $37{ }^{\circ} \mathrm{C}$ under an atmosphere of $5 \% \mathrm{CO} 2$.

\section{Reagents and antibodies}

CPS ([N-(4-hydroxy-3-methoxy-phenyl)methyl]-8-methyl-6-nonenamide), and capsazepine (CPZ) (N-[2-(4chlorophenyl)ethyl]-1,3,4,5-tetrahydro-7,8-dihydroxy2H -2-benzazepine-2-carbothioamide), were purchased from Cayman Chemical Company (Michigan, USA). CCK8 (Roche Biochemicals, Mannheim, Germany), and dimethyl sulfoxide (DMSO) were purchased from SigmaAldrich (St. Louis, MO). Anti-TRPV1 specific antibody (1:200, \#ACC-030) was purchased from Alomone Labs (Jerusalem, Israel) and anti-GAPDH specific antibody (1:1000, sc-166574) was purchased from Santa Cruz
Biotechnology (USA). Antibody against c-myc (1:1000, \#ab32072) was from Abcam (Cambridge, UK). Antibodies against Bcl2 (1:1000, \#12789-1-AP), Bax (1:1000, \#50599-2Ig) were purchased from Proteintech (Chicago, IL, USA). Antibodies against p-ERK1/2 (1:2000, \#4370P), total ERK1/ 2 (1:2000, \#4695P), p-JNK (1:1000, \#4668P), total JNK (1:1000, \#9258P), p-P38 (1:1000, \#4511P), total P38 (1:1000, \#9212P), FADD (1:1000, \#2782), and caspase-3 (1:500, \#9665), caspase-8 (1:1000, \#9496), caspase-9 (1:1000, \#9502) were obtained from Cell Signaling Technologies (Danvers, MA).

\section{RT-PCR}

Total RNA was isolated from 786-O cells using the TRIzol Reagent (Invitrogen). For reverse transcriptase (RT) analysis, $3 \mu \mathrm{g}$ of RNA was reverse transcribed into cDNA using RevertAid Fist Strand cDNA Synthesis Kit (Thermo Scientific). PCR was performed by adding $2 \mu \mathrm{l}$ $\mathrm{RT}$ reaction mixture in a final volume of $50 \mu \mathrm{l}$. DNA amplification conditions included an initial $5 \mathrm{~min}$ denaturation step at $95{ }^{\circ} \mathrm{C}$ and 35 cycles of $30 \mathrm{~s}$ at $95{ }^{\circ} \mathrm{C}$, $30 \mathrm{~s}$ at $60{ }^{\circ} \mathrm{C}$, and $60 \mathrm{~s}$ at $72{ }^{\circ} \mathrm{C}$, and finally $5 \mathrm{~min}$ at $72{ }^{\circ} \mathrm{C}$. PCR primers used were designed as follows: TRPV1 forward primer: 5' -TTCCGA GGG ATT CAG TAT TT-3' and reverse primer: $5^{\prime}$-TGA GCA GGA GGA TGT AGG TG-3'; $\beta$ actin forward primer: 5'-AGA AGG ATT CCT ATG TGG GCG-3'and reverse primer: 5'-CAT GTC GTC CCA GTT GGT GAC-3'.

\section{Western blot assay}

Cells were washed three times with ice-cold PBS and underwent lysis in $1 \%$ Triton lysis buffer on ice, then quantified with BCA kit. For each sample, 10-50 g protein was separated on 10-15\% SDS-PAGE (Promoton Biotechnology, Shanghai, China) and transferred onto PVDF membrane (Millipore, Bedford). Membranes were incubated with primary antibodies overnight at $4{ }^{\circ} \mathrm{C}$ followed by HRP-conjugated secondary antibodies at $37{ }^{\circ} \mathrm{C}$ for $2 \mathrm{~h}$, and developed with the WesternBright ECL HRP substrate (Advansta).

\section{CCK8 assay}

Cell growth and viability were measured using cell proliferation and cytotoxicity reagent WST-8 (Roche Biochemicals, Mannheim, Germany). Briefly, the protocol was as follows: $786-\mathrm{O}, \mathrm{ACHN}$, Caki-1 cells $\left(5 \times 10^{3}\right.$ per well) were cultured in a 96-well plate. After $12 \mathrm{~h}$ (time for cells to attach to the plate surface), cells were treated with different concentrations of CPS $(0-400 \mu \mathrm{M})$ or pretreated with CPZ $(2 \mu \mathrm{M})$ for $2 \mathrm{~h}$ and then treated with CPS, ten wells each group for statistics. At the harvest time $10 \mu \mathrm{l}$ of CCK8 was added into each well and after one hour's incubation cell viability was determined by measuring the 
absorbance of the converted dye at $490 \mathrm{~nm}$. The experiments were triplicate.

\section{Analysis of LDH release activity and ROS generation}

Lactate dehydrogenase (LDH) release assay was employed to assess cell death according to the manufacturers' recommendations (Beyotime Institute of Biotechnology, Nantong, China). The assay was quantitated by determining the absorbance at $490 \mathrm{~nm}$. Reactive Oxygen Species (ROS)-sensitive fluorescent probe, DCFH-DA was used to assess intracellular production of ROS in 786-O, ACHN, and Caki-1 cells treated with CPS, following a microplate assay procedure. The non-fluorescent DCFH-DA probe enters a cell, and is hydrolyzed by cellular esterases, subsequently oxidated by ROS in the cell, which change to a fluorescent form. 786-O, ACHN, and Caki-1 cells were cultured in 96-well plate $\left(1 \times 10^{4}\right.$ cells per well $)$ and treated with different concentrations of CPS for $24 \mathrm{~h}$, with/without being pretreated with CPZ. Afterwards, the probe DCFHDA was added to a final concentration of $10 \mu \mathrm{M}$ in RMPI 1640 medium and then incubated at $37^{\circ} \mathrm{C}$ without exposure to light for $20 \mathrm{~min}$. After washed at least three times with culture medium, fluorescence enzyme-linked immunoassay reader was used to measure the mean RFU of each plate (emission at $525 \mathrm{~nm}$ with excitation at $488 \mathrm{~nm}$ ).

\section{Analysis of apoptosis with flow cytometry and hochest 33258 Nuclear Staining}

For analysis of apoptosis, after indicated time of CPS incubation, 786-O, ACHN, and Caki-1 cells were

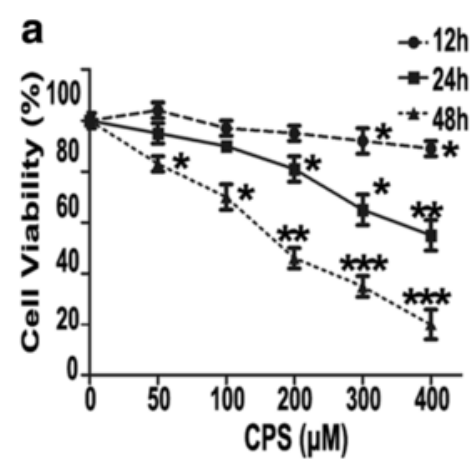

C
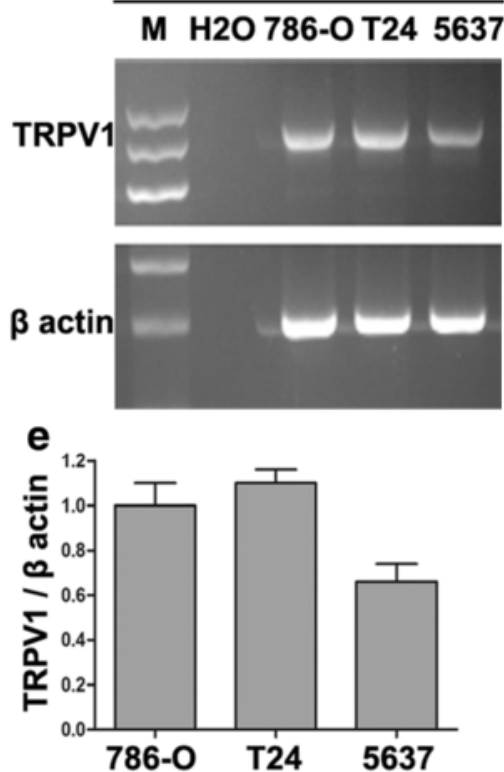

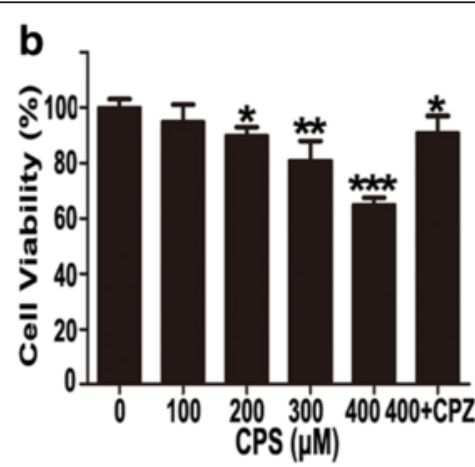

d

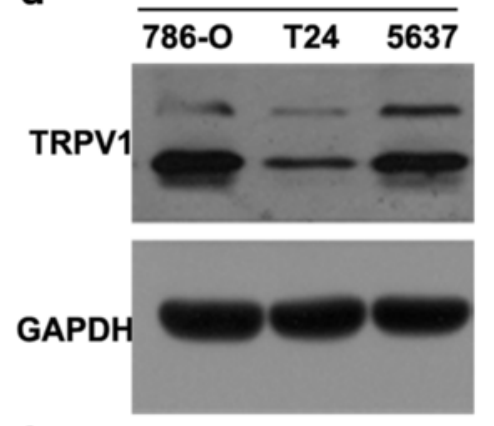

f

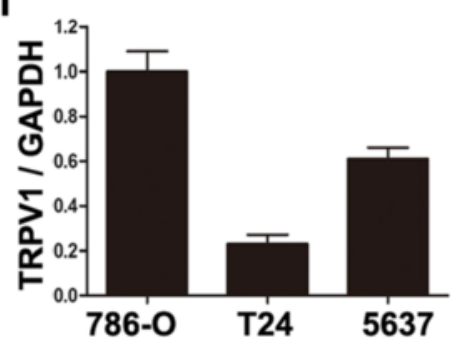

Fig. 1 CPS decreased the viability of 786-O cells. a Cell viabilities were determined after 786-O cells was incubated with vehicle (0.1\% DMSO) or different concentrations of CPS for 12, 24, $48 \mathrm{~h}$ by CCK8 assay, and are expressed as percent against control, which was taken as $100 \%$, and treated with medium-containing vehicle (0.1\% DMSO). b Pretreatment of CPZ at $2 \mu \mathrm{M}$ for $2 \mathrm{~h}$ significantly attenuated the decreasing of cell viability by $48 \mathrm{~h}$ incubation of CPS. All of the CCK8 assays were conducted in triplicate. $\mathbf{c}$ and $\mathbf{d}$ The expression of TRPV1 in 786-O, T24, and 5637 cells was detected by RT-PCR (c) and western blot (d). $\beta$ actin and GAPDH were used as internal standards in RT-PCR and western blot, respectively. e and $\mathbf{f}$ TRPV1 expression was quantified and the results of RT-PCR (e) and western blot (f) were presented in histograms. Expression of TRPV1 in different cells was normalized over 786-O cells. ${ }^{*} P<0.05,{ }^{* *} P<0.01,{ }^{* * *} P<0.001 ;$ bars, SD. One-Way ANOVA was used for the data analysis 
collected with trypsin and incubated in a binding buffer containing FITC-conjugated annexin V and PI at room temperature for $5 \mathrm{~min}$ in the dark and detected with flow cytometry analysis. To visualize apoptotic bodies, 786-O cells were exposed to different concentrations of CPS for $24 \mathrm{~h}$, fixed in $4 \%$ paraformaldehyde and stained with $1 \mathrm{ml}$ $10 \mu \mathrm{g} / \mathrm{ml}$ Hochest 33258 (Sigma) for $30 \mathrm{~min}$ at $37{ }^{\circ} \mathrm{C}$ in the dark. After thoroughly washed with PBS, the cells were checked for karyopyknosis under the inverted fluorescence microscope.

\section{In vivo animal treatment protocol}

Athymic nude (nu/nu) 5-week-old mice were supplied by Experimental Centre of Medical Scientific Academy of Hubei province. The animal study was performed in the Animal Biosafety Level 3 Laboratory of Wuhan University (Wuhan, China) accredited by the AAALAC International. The animal protocol used in this study was approved by local ethics committee (Ethical Committee of Zhongnan Hospital, Wuhan University, IRB ID: 2012030), and was in accordance with the ARRIVE guidelines and the Guide for the Care and Use of Laboratory Animals (eighth edition) by the National Research Council of the United States National Academies. All mice were housed in alaminar air-flow cabinet under pathogen-free conditions with a $12 \mathrm{~h}$ light/dark schedule at controlled temperature and humidity with food and water ad libitum. After acclimated for one week prior to study initiation, mice were then were injected subcutaneously into the right flank with $1 \times 10^{7} 786-\mathrm{O}$ cells in $0.1 \mathrm{ml}$ of sterile PBS. Six weeks post-inoculation, mice were divided into two experimental groups $(n=10$ per group) based on the initial tumor volume, the CPS group with treatment of CPS $5 \mathrm{mg} / \mathrm{kg}$ in $100 \mu \mathrm{l}$ of PBS containing $0.1 \%$ DMSO and the control group received 100ul PBS containing $0.1 \%$ DMSO. The injection was repeated by gavage every three days for a total of 4 weeks until the mice were sacrificed. Mice were monitored daily for tumor growth (using digital calipers), hair coat, overall activity and body weight. Then, all the mice were sacrificed by cervical dislocation, under anaesthetization using diethyl ether through inhalation. Tumor volumes were calculated by the formula: 1/2(Length $\left.\times W i d t h^{2}\right)$. The proliferating tumor cells were detected by proliferating cell nuclear antigen (PCNA) and Ki-67 staining. The evaluation of PCNA and Ki-67 expression was based on the proportion of positively stained cells, in which the cell nuclei were stained dark brown, among a total of 1000 counted cells. The apoptosis rate was determined by terminal deoxynucleotidyl transferase (TdT) dUTP nick-end labelling (TUNEL) reaction technique, and the percentage of labeled nuclei was then calculated and defined as numbers of brown apoptosis bodies in each field. All sections of this report adhere to the ARRIVE Guidelines for reporting animal research [17]. A completed ARRIVE guidelines checklist is included in Additional file 1: Checklist S1.

\section{Statistical analysis}

SPSS version 13.0 (University of Nevada, Las Vegas, NV, USA) was used for the statistical analysis. All data is presented as mean $\pm \mathrm{SD}$. Statistical analysis was performed using One-Way ANOVA, with $P<0.05$ taken as statistically significant.
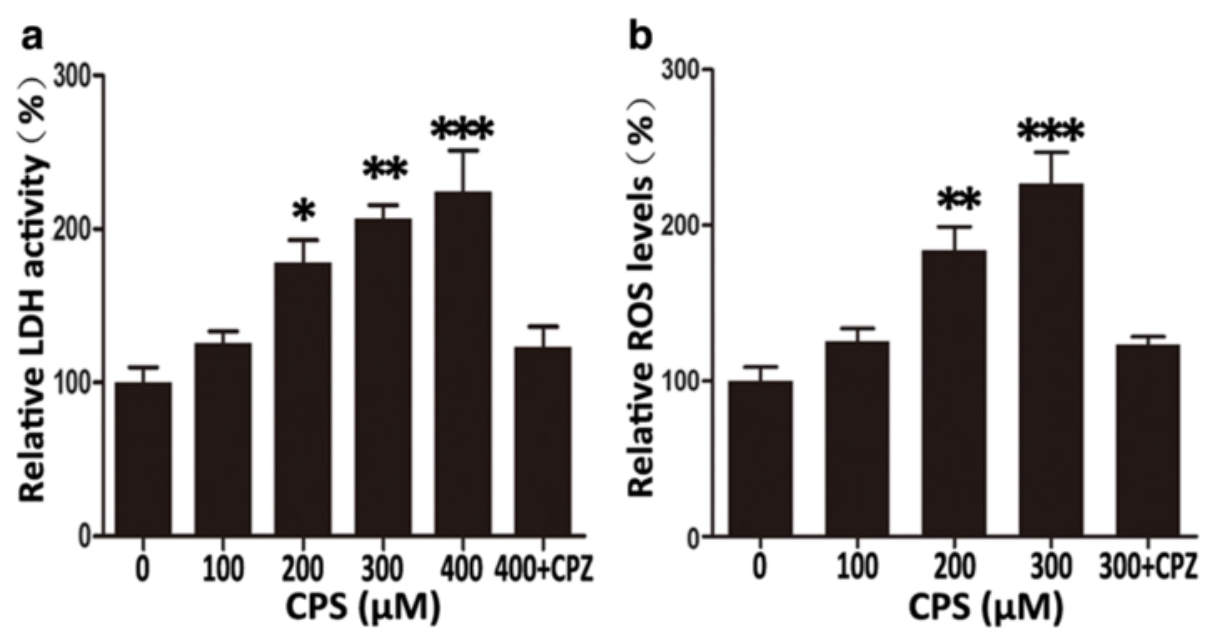

Fig. 2 CPS increased LDH release activity and ROS Generation in 786-O cells. a LDH release assays with 786-O cells treated with different concentrations of CPS (from 100 to $400 \mu \mathrm{M}$ ) for 72 h, or with $400 \mu \mathrm{M}$ CPS for $72 \mathrm{~h}$ after being pretreated with $2 \mu \mathrm{M}$ CPZ for 2 h. b DCFHDA fluorescence images are shown with the fluorescence intensity representing ROS concentration. Cells stimulated with vary concentrations (from 100 to $300 \mu \mathrm{M}$ ) of CPS for $24 \mathrm{~h}$, or with $300 \mu \mathrm{M}$ CPS after being pretreated with CPZ. Statistical data from multiple experiments (mean \pm SD, $n=30$ ). ${ }^{*} P<0.05$, ${ }^{*} P<0.01,{ }^{* *} P<0.001$; bars, SD. One-Way ANOVA was used for the data analysis 

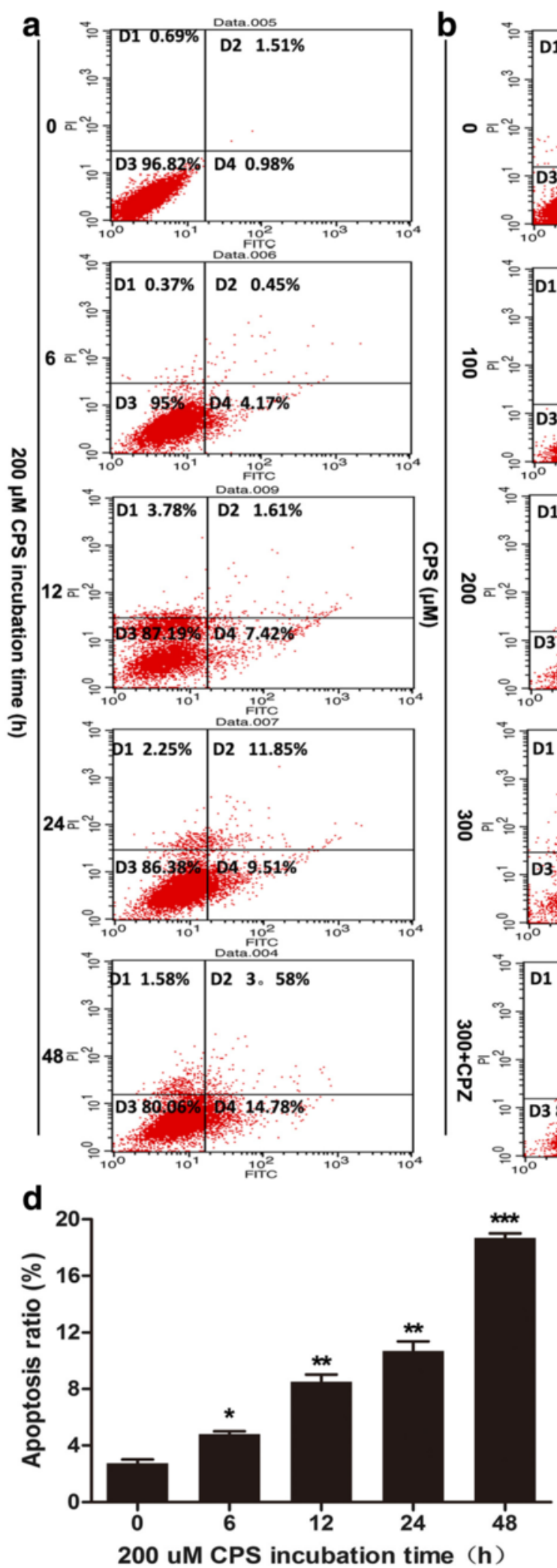
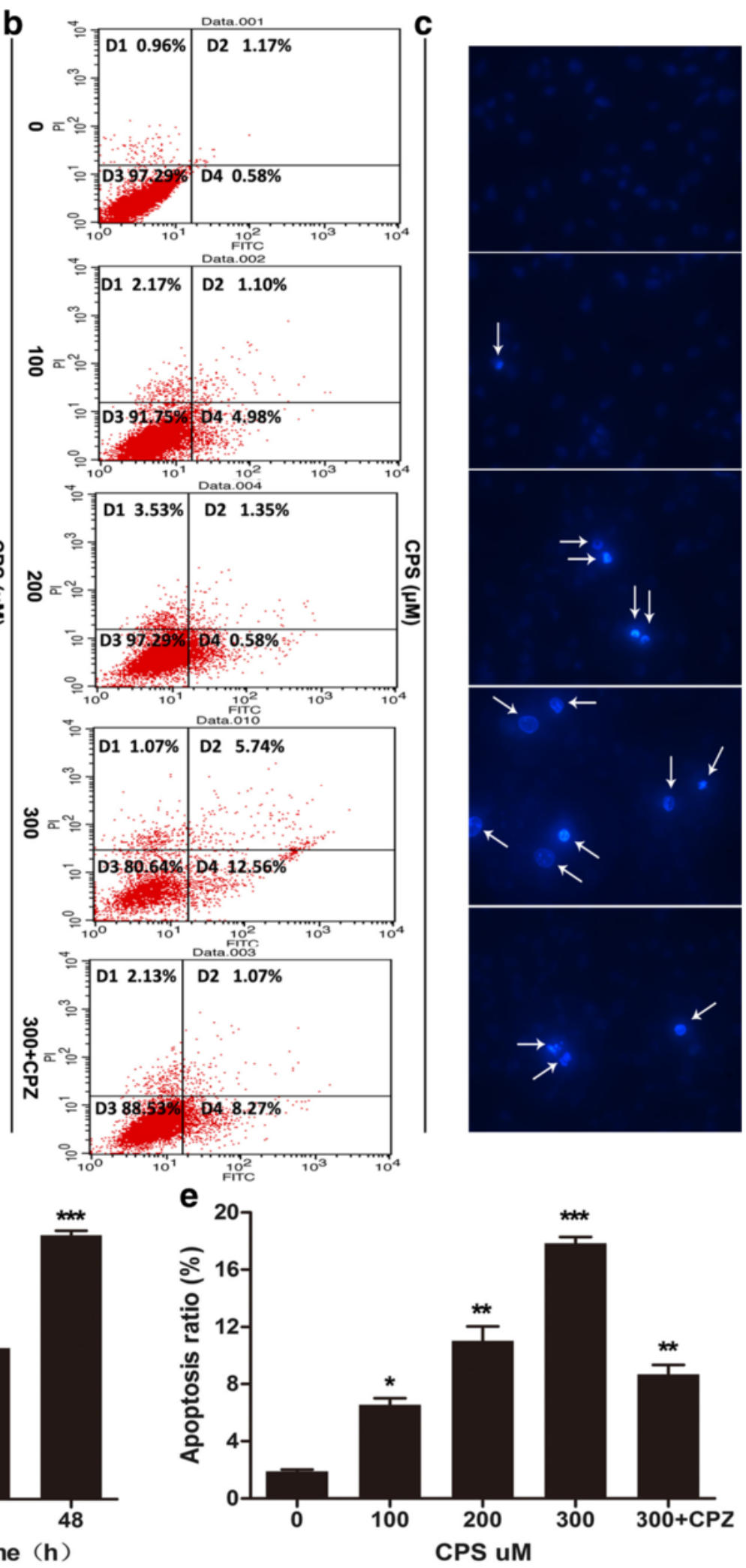

Fig. 3 (See legend on next page.) 
(See figure on previous page.)

Fig. 3 CPS induced apoptosis in 786-O cells. $\mathbf{a}$ and $\mathbf{b} 786-0$ cells were treated with vary concentrations of CPS, or pretreated with $2 \mu \mathrm{M}$ CPZ for $2 \mathrm{~h}$ and then treated with $300 \mu \mathrm{M}$ CPS for $24 \mathrm{~h}$ (b), or treated with $300 \mu \mathrm{M}$ CPS for $0,6,12,24$, or $48 \mathrm{~h}$ (a). Then, cells were collected and incubated in a binding buffer containing FITC-conjugated annexin-V, and PI was then detected with flow cytometry analysis. c The hochest 33258 staining assay revealed that CPS facilitated cell apoptosis in 786-O cells. Arrows indicate apoptotic cells. $\mathbf{d}$ and $\mathbf{e}$ The quantitative data showed the percentage of apoptotic cells in A and B. ${ }^{*} P<0.05,{ }^{* *} P<0.01,{ }^{* *} P<0.001$; bars, SD. One-Way ANOVA was used for the data analysis

\section{Results}

\section{CPS decreased the viability of $786-0$ cells}

The cytotoxic effect on cell proliferation of CPS on 786-O cells was measured by CCK8 assays. 786-O cells were treated with varying concentrations (from 0 to $400 \mu \mathrm{M}$ ) of CPS for 12,24 or $48 \mathrm{~h}$, respectively. Cell viability curves showed that CPS inhibited the proliferation of 786-O cells in both dose- and time-dependent manners. In $48 \mathrm{~h}$ group, cell viability in DMSO-treated cells was taken as $100 \%$, and CPS at 50, 100, 200, 300 and $400 \mu \mathrm{M}$ decreased the cell viability by $7.20,15.91,50.96,62.40$, and $76.77 \%$, respectively, which indicated an approximate $\mathrm{IC}_{50}$ of $200 \mu \mathrm{M}$. And when cells were incubated with $200 \mu \mathrm{M}$ CPS, cell viabilities at 12,24 , and $48 \mathrm{~h}$ were decreased by 4.2, 20.77, and $50.90 \%$, respectively (Fig. 1a). The proliferation of $\mathrm{ACHN}$, and Caki-1 cells were also found to be inhibited by CPS in a dose-dependent manner (Additional file 2: Figure S1).

We then detected whether the anti-proliferative effect of CPS in our model also referred to its targeted binding to TRPV1. As shown in Fig. 1b, pretreated CPZ at $2 \mu \mathrm{M}$ for $2 \mathrm{~h}$ partially attenuated the cytotoxic effect of CPS, indicating that TRPV1 partially mediated CPS-induced proliferative suppression. Besides, we also detected expression of TRPV1 in 786-O cells, finding that TRPV1 expressed in 786-O at both mRNA and protein levels (Fig. 1c, d, e and f).

\section{CPS increased LDH release activity and ROS generation}

The cytotoxic activity of CPS was further confirmed by $\mathrm{LDH}$ release assays. Increased LDH activity was observed in CPS-treated 786-O cells in a dose-dependent manner (Fig. 2a). Compared with normal control, 200, 300 , and $400 \mu \mathrm{M}$ of CPS increased the LDH release activity of $786-\mathrm{O}$ cells by $77.58,106.87$, and $124.33 \%$, respectively, whereas there were no significant changes in cells treated with CPS $+\mathrm{CPZ}$ (pretreatment of $2 \mu \mathrm{M}$ $\mathrm{CPZ}$ for $2 \mathrm{~h}$, and then $400 \mu \mathrm{M}$ CPS for another $72 \mathrm{~h}$ ) or cells treated with DMSO or $100 \mu \mathrm{M}$ CPS (Fig. 2a). We also determined whether CPS induced generation of ROS both by ROS Kit and flow cytometry analysis. In ROS Kit assays, after stimulation, CPS at 100, 200, and $300 \mu \mathrm{M}$ increased the ROS generation by $25.35,83.74$, and $162.80 \%$, respectively, which could be partially abolished by CPZ (Fig. 2b). By flow cytometry analysis, we found CPS induced significant increase of ROS generation in 786-O cells at the concentration of 200, and
$300 \mu \mathrm{M}$, and in ACHN cells of $300 \mu \mathrm{M}$, while in Caki-1 cells CPS failed to induce significant increase of ROS generation (Additional file 3: Figure S2).

\section{CPS induced apoptosis in 786-0 cells}

In order to ascertain the precise mechanisms of the anticancer activity of CPS, cell apoptosis was detected by flow cytometry analysis. As shown in Fig. 3a and b, CPS triggered apoptosis in both time- and dose-dependent manners. At the concentration of $200 \mu \mathrm{M}$, in comparison with the control, CPS increased apoptosis by 1.13 , $6.54,8.88$, and $15.87 \%$ after $6,12,24,48 \mathrm{~h}$ incubation, respectively (Fig. 3a and d). As shown in Fig. 3b and e, CPS also caused cell apoptosis in a dose-dependent manner, and at the dose of 0, 100, 200 and $300 \mu \mathrm{M}$, CPS induced 1.80, 6.10, 9.30 and $12.00 \%$ apoptosis, respectively, after $24 \mathrm{~h}$ treatment. However, CPZ could also decrease CPS-induced apoptosis (Fig. 3e). To further confirm apoptotic cell death, we examined nuclear morphological changes using Hochest 33258 staining. After stimulation of CPS, 786-O cells exhibited obviously condensed and fragmented nuclei, while $\mathrm{CPZ}$ partially reverted the change of cell morphology (Fig. 3c). In addition, CPS decreased the expression of $\mathrm{Ki}-67$ but increased the TUNEL staining in RCC cells (Additional file 4: Figure S3). These data clearly demonstrated that CPS induced apoptosis in 786-O cells.

In an attempt to gain further insight into the mechanism underlying CPS-induced apoptosis of 786-O cells, we investigated the protein levels of several key apoptosislinked gene products, such as c-myc, FADD, Bcl2 and Bax. Expression of the pro-apoptotic c-myc, FADD, and Bax were up-regulated by CPS in a dose-dependent manner, while the anti-apoptotic Bcl2 down-regulated (Fig. 4a and c). Caspase families including caspase-3, -8, and -9 were also tested by western blot assays. As Fig. $4 \mathrm{~b}$ and d showed, exposure to CPS $(0-300 \mu \mathrm{M})$ for $24 \mathrm{~h}$ caused dose-dependent increase of the cleaved fragments of caspase-3, -8, and -9. Moreover, CPS (200 $\mu \mathrm{M})$ treatment also resulted in a time-dependent increase of cleaved caspase-3, -8, and -9 (Fig. 4e and f). These results suggested that CPS could modulate the activation of the caspase apoptotic signaling pathways in 786-O cells.

\section{P38 and JNK MAPK signaling pathways mediated CPS-induced apoptosis}

Further, we determined whether MAPKs were implicated in the anti-cancer effect of CPS on 786-O cells. 


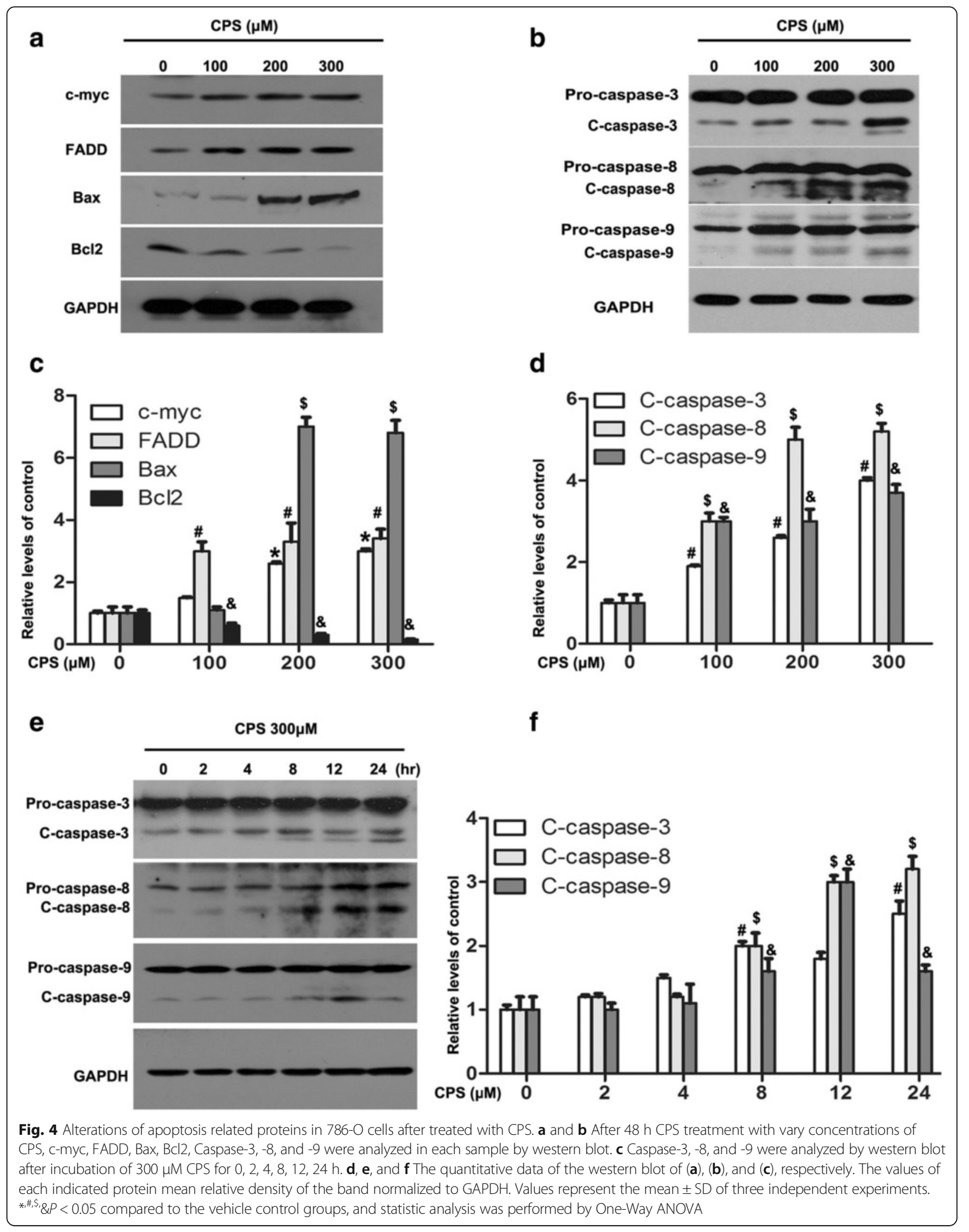


We found that p-ERK1/2 (phosphorylated form of ERK1/2) was decreased, while p-P38 and p-JNK (phosphorylated form of P38 and JNK) increased substantially in cells treated with CPS, in a dose-dependent manner
(Fig. 5a and c). Moreover, CPS (200uM) treatment also presented a time-dependent decrease of p-ERK $1 / 2$, yet a time-dependent increase of p-P38 and p-JNK (Fig. 5b and d). To confirm the involvement of the MAPKs, we

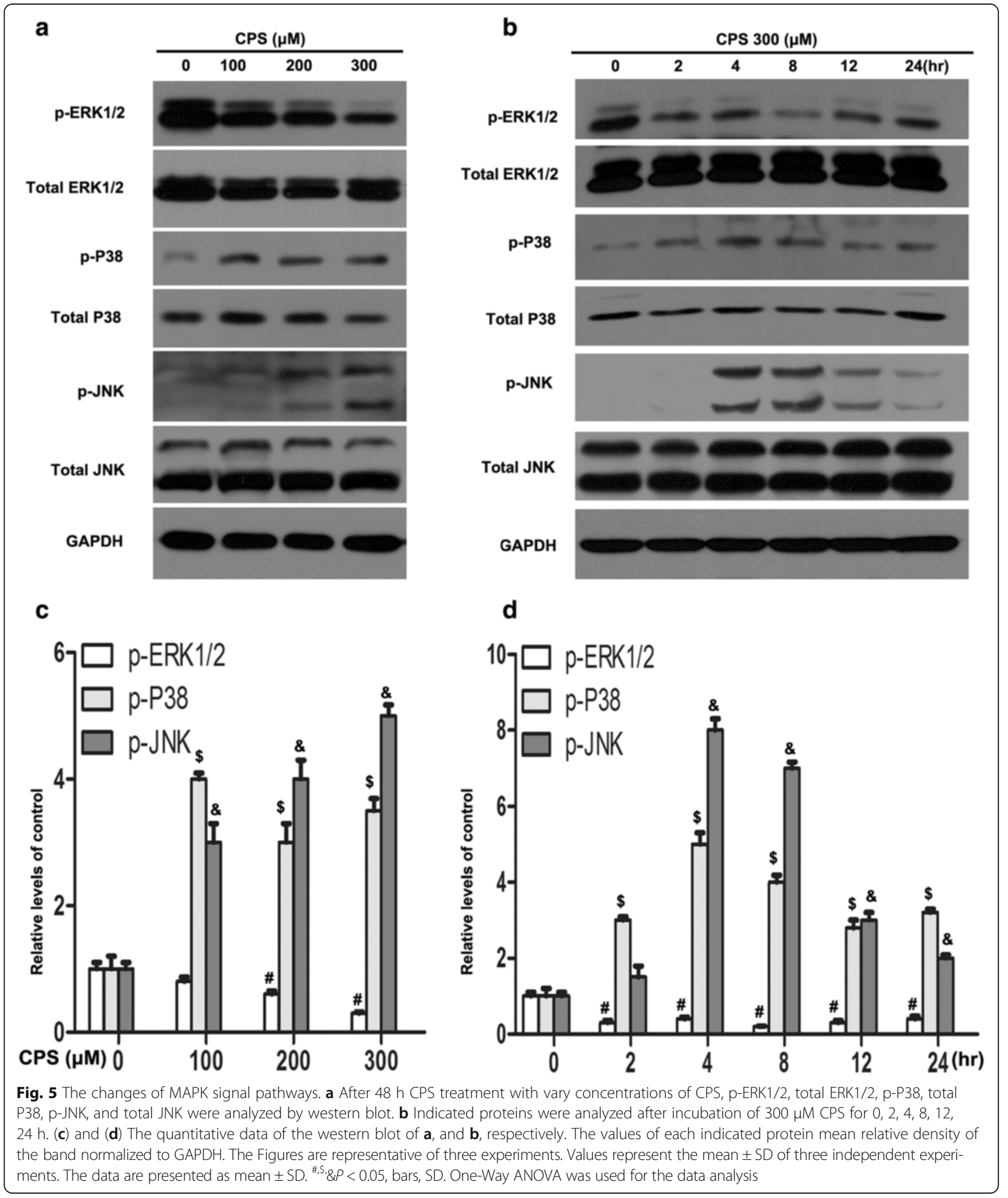


analyzed the effects of the P38 inhibitor (SB203580, $20 \mu \mathrm{M})$ and JNK inhibitor (SP600125, $10 \mu \mathrm{M}$ ) on the CPS-mediated proliferative inhibition by CCK8 assays. The anti-proliferative activity was dramatically affected by SB203580 and SP600125 (Fig. 6a).

Next, we further investigated relationships between CPS-induced alteration of MAPKs and activation of caspase-3, -8, and -9. 786-O cells were pretreated with SB203580, or SP600125 for $4 \mathrm{~h}$, treated with $300 \mu \mathrm{M}$ CPS for another $24 \mathrm{~h}$, and then analyzed by western blot. As shown in Fig. 6b, c, d and e, treatment of SB203580, or SP600125 significantly attenuated CPS-induced activation of caspase- $3,-8$, and -9 , which suggested that activation of P38 and JNK MAPKs might play a critical upstream role in mediating CPS-induced caspases activation.

\section{CPS slowed the growth of 786-0 xenografts in vivo}

To extend the observations made in cultured cells and to assess the efficacy of CPS in vivo, its effect on the growth of 786-O renal tumor xenografts was determined in athymic nude mice. 786-O xenograft models showed dramatic response to CPS, with a significant reduction in tumor volume and weight (Fig. 7a and b), on comparison with vehicle treatment. The mean body weight and hair coats, as well as overall activity, were similar in both groups at the termination of the experiment, suggesting that CPS had no major negative effects on these mice (data not shown). As a result, tumors from CPStreated mice exhibited notably lower expression of PCNA and Ki67 by immunohistochemical staining compared with tumors from control mice (Fig. 7c, d, and e), which confirmed a significant decrease in proliferation of tumor xenografts by CPS. In addition, higher count of brown apoptotic bodies were observed in tumors from CPS-treated mice by TUNEL, suggesting apoptosis was a possible mechanism for tumor growth inhibition (Fig. 7c, and f). These results positively corresponded with our in vitro studies.

\section{Discussion}

$\mathrm{RCC}$ is one of the most refractory tumors to chemotherapy to date. Therefore, novel therapeutic agents are urgently needed for this disease. In the last decade, the role of CPS in tumoral growth and cell transformation represents a much-discussed question in scientific literature [18, 19]. CPS shows the ability to induce apoptosis and cell cycle arrest and suppress metabolic activation in transformed cells $[20,21]$. However, whether CPS has anti-cancer activity in human RCC keeps unknown. The present manuscript fills this void of knowledge and explores the chemopreventive

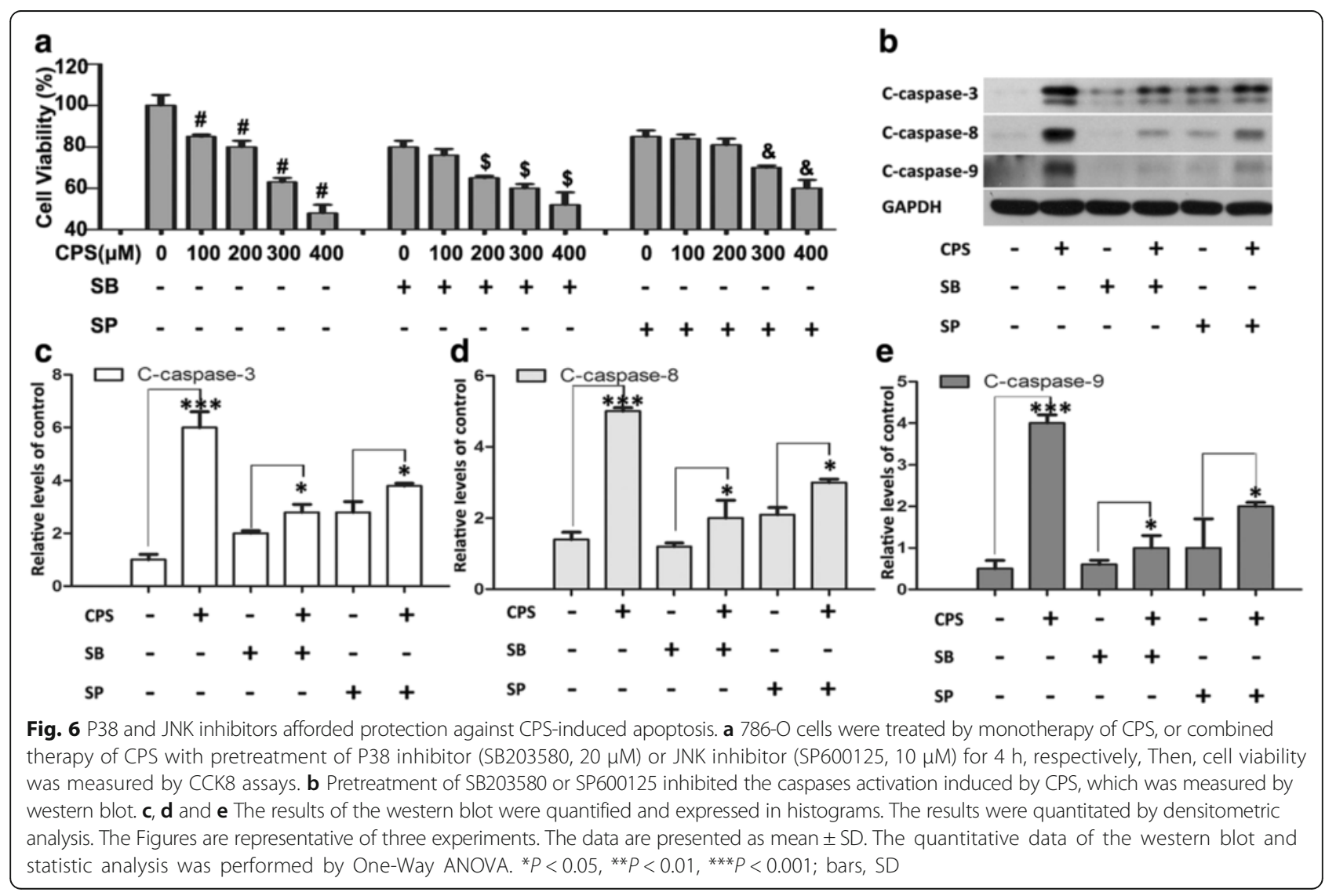




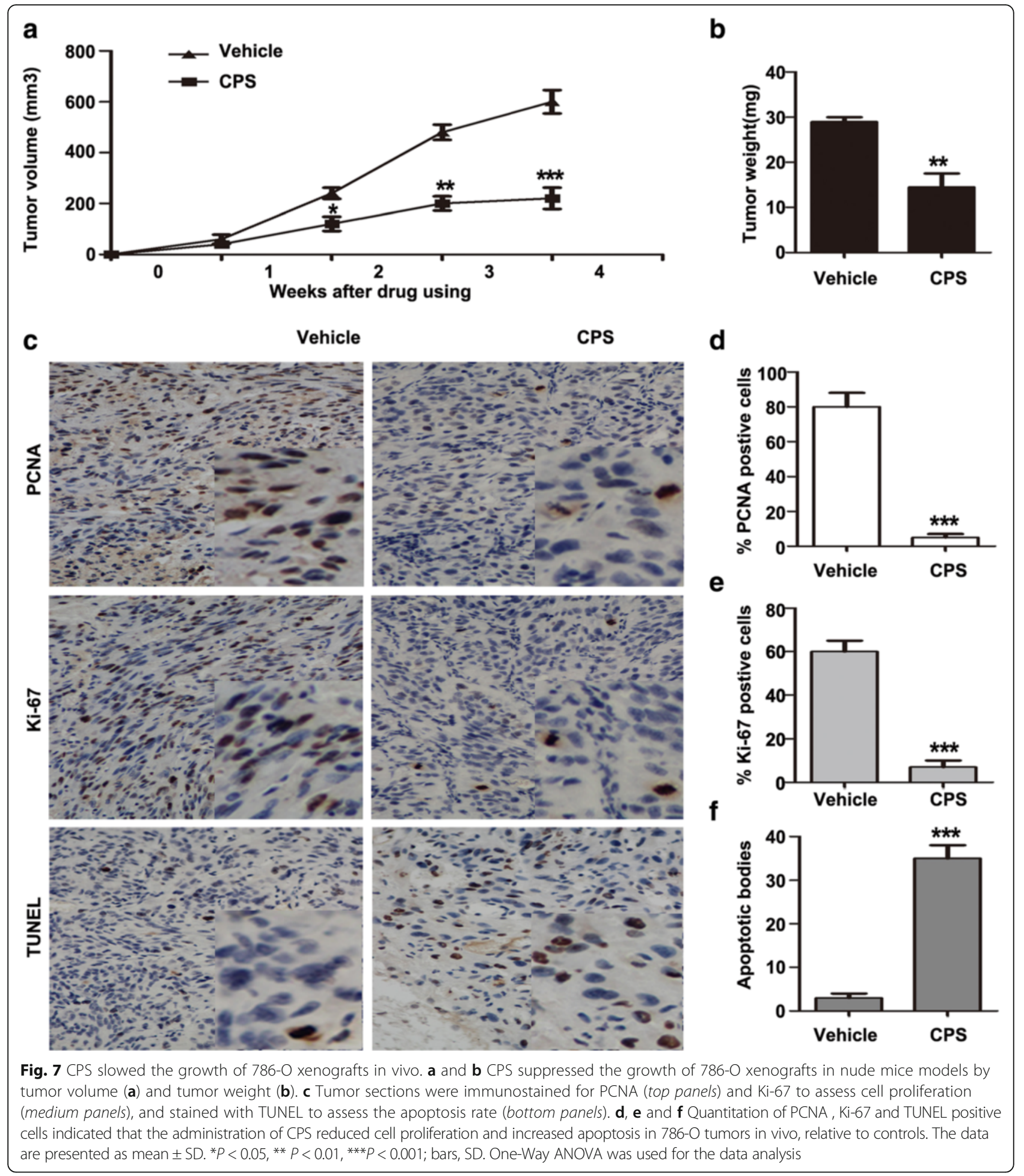

potential of CPS in RCC 786-O cells. To our knowledge, our pilot study showed for the first time that CPS displayed potent anti-cancer activity in human RCC. The antiproliferative activity of CPS was confirmed by substantial increase of LDH release activity and ROS generation, which were partially attenuated by $\mathrm{CPZ}$ (a representative antagonist of TRPV1). As a nonselective and ligand-gated cationic channel receptor, TRPV1 had recently been shown involved in malignant cell growth and progression by controlling cell survival and apoptotic cell death [22, 23]. We found that TRPV1 expressed in 786-O at both mRNA and protein levels, and two bladder cancer lines T24 and 5637 
were taken as the positive controls of TRPV1 expression, which were verified in the previous studies of our research team $[24,25]$. These results suggested that CPS induced increase of LDH release activity and ROS generation partially via activating TRPV1.

Efforts have been made to develop chemoprevention strategies that trigger apoptosis of malignant cancer cells $[26,27]$. Apoptosis, known as an encoded suicide program, is arguably the most potent natural defense against cancer [28], and resistance to apoptosis is considered as a hallmark of cancer. What's more, the majority of studies exploring the anti-cancer activity of CPS have focused on the mechanisms underlying CPS-induced apoptosis $[29,30]$. In the present study, we observed significant apoptosis of 786-O cells by CPS treatment, which was also attenuated by pretreatment of CPZ. Besides, we found rapid up-regulation of pro-apoptotic genes including c-myc, FADD, Bax and, while down-regulation of anti-apoptotic gene $\mathrm{Bcl} 2$ which eventually led to the activation of caspase- $3,-8$, and -9 cascade, suggesting that CPS-induced apoptosis might partly occured through a mitochondrion-mediated pathway. Bcl2, an anti-apoptotic oncoprotein, has been shown to act on mitochondria and prevent the release of cytochrome $\mathrm{c}$ and thus caspases activation, while Bax mediated exactly opposite processes [31, 32]. The ratio of $\mathrm{Bcl} 2$ to $\mathrm{Bax}$, rather than the levels of the individual proteins, is considered to be critical in determining the survival or death of cells [33]. We showed that $\mathrm{Bcl} 2$ was decreased while Bax increased thus the ratio of Bcl2 and Bax decreased dramatically by CPS, which may induce apoptotic response. In addition, apoptosis is also mediated by proteolytic enzymes called caspases, which trigger cell death by cleaving specific proteins in the cytoplasm and nucleus [34]. We observed that significant activation of caspase- $3,-8$ and -9 occurred after treatment with CPS.

Some evidence suggests that MAPK signaling pathways play an important role in the action of some chemotherapeutic drugs in the regulation of apoptosis [34, 35]. It was found that CPS could increase P38 phosphorylation, and JNK phosphorylation, thus promoting apoptosis [36, 37]. Some other papers also showed CPS could alter MAPK pathways [38]. On the basis of previous reports, we further investigated activation of MAPKs in our study. We found p-ERK1/2 down-regulated while p-P38 and pJNK increased substantially in CPS-treated 786-O cells. Nonetheless, pre-treatment with P38 inhibitor (SB203580, 20uM) and JNK inhibitor (SP600125, $10 \mu \mathrm{M})$ effectively inhibited CPS-induced activation of caspase-3, -8 , and -9 , thus inhibited apoptosis and recovered cell viability. Taken together, these results suggested that activation of P38 and JNK MAPKs played an important role in CPS-induced apoptosis.

Whether these in vitro observations has any relevance to that in vivo was also investigated. Our results showed that CPS possessed a profound anti-proliferation effect on 786-O xenograft renal tumors without major side effects on these nude mice.

\section{Conclusions}

In conclusion, we are the first to explore the anti-cancer potential of CPS in renal cell carcinoma. We found treatment of CPS reduced proliferation of 786-O cells, and induced obvious apoptosis. These events were associated with substantial up-regulation of pro-apoptotic genes including c-myc, FADD, Bax and cleaved-caspase-3, -8, and -9 , while down-regulation of anti-apoptotic gene Bcl2. Besides, CPS-treatment activated P38 and JNK MAPK pathways, yet P38 and JNK inhibitors afforded protection against CPS-induced apoptosis by abolishing activation of caspase-3, -8 , and -9 . Furthermore, CPS significantly slowed the growth of 786-O renal cancer xenografts in vivo. Such results reveal that CPS is an efficient and potential drug for management of human RCC. Therefore, CPS shows brilliant antitumor properties, thus represents promising drugs against renal cell carcinoma and should thus be explored additionally for therapeutic use.

\section{Additional files}

\begin{abstract}
Additional file 1: NC3Rs ARRIVE Guidelines Checklist. (PDF 1527 kb)
Additional file 2: Figure S1. CPS decreased the viability and induced apoptosis of ACHN and Caki-1 cells. A: Cell viabilities were determined after ACHN and Caki-1 cells was incubated with vehicle (0.1\% DMSO) or different concentrations of CPS for $48 \mathrm{~h}$ by CCK8 assay, and are expressed as percent against control, which was taken as $100 \%$, and treated with medium-containing vehicle ( $0.1 \% \mathrm{DMSO})$. B: ACHN and Caki-1 cells were treated with vary concentrations of CPS for $24 \mathrm{~h}$. Then, cells were collected and analyzed by flow cytometry analysis. C: The quantitative data showed the percentage of apoptotic cells in $(C) .{ }^{*} \# P<0.05, * *, \# \#, \$ \$, \& \& P<0.01$, ***,\#\#\#\$\$.\&\&\&P<0.001; bars, SD. One-Way ANOVA was used for the data analysis. (JPG $800 \mathrm{~kb}$ )
\end{abstract}

Additional file 3: Figure S2. CPS increased ROS Generation in RCC cells. A: Flow cytometry analysis for 786-O, ACHN, and Caki-1 cells stained with DCFH-DA, and statistically analyzed in (B), revealing an increased ROS in the RCC cells. C: DCFH-DA stained (green) 786-O, ACHN, and Caki-1 cells after CPS and vehicle treatment. Nuclears were stained by DAPI (blue). The images were photographed by fluorescence microscope and scale bars for (C) are $20 \mu \mathrm{m} .{ }^{\#} P<0.05,{ }^{*} P<0.01,{ }^{* * *} P<0.001$; bars, SD. One-Way ANOVA was used for the data analysis. (JPG $587 \mathrm{~kb})$

Additional file 4: Figure S3. CPS decreased the expression of Ki-67 but increased the TUNEL staining in RCC cells. A: Immunofluorescence staining of Ki-67 (green) in ACHN, and Caki-1 cells after CPS and vehicle treatment. B: Immunofluorescence staining of TUNEL (green) in 786-O, ACHN, and Caki-1 cells. Nuclears were stained by DAPI (blue). The images were photographed by fluorescence microscopy. The scale bar for C and D is $20 \mu \mathrm{m}$. (JPG $693 \mathrm{~kb}$ )

\section{Abbreviations}

CPS: Capsaicin; CPZ: Capsazepine; DMSO: Dimethyl sulfoxide; RCC: Renal cell carcinoma; RT: Reverse transcriptase; TRPV1: Transient receptor potential vanilloid type 1; TUNEL: Terminal deoxynucleotidyl transferase (TdT) dUTP nick-end labelling

Acknowledgments

Not applicable. 


\section{Funding}

This study was supported by two grants of Natural Science Foundation of China (No.81172434 and No. 81202027), one grant of Research Fund for the Doctoral Program of Higher Education of China (No. 20130141110038), and one grant of Project of Jingzhou Municipal Science and Technology Bureau (No. 2013031).

\section{Availability of data and materials}

The datasets during and/or analysed during the current study available from the corresponding author on reasonable request.

\section{Authors' contributions}

XXW and JJZ study conception and design, Cell-based and molecular assays, Collection and assembly of data, data analysis and interpretation, Manuscript writing. TL \& GW \& HHT collection and/or assembly of data, Data analysis and interpretation. ZHY data analysis and interpretation. YZW \& ZM collection and/ or assembly of data. RC \& YX study design, data analysis and interpretation, final manuscript review. All authors read and approved the final manuscript.

\section{Authors' information}

Not applicable.

\section{Competing interests}

The authors declare that they have no competing interests.

\section{Consent for publication}

Not applicable.

\section{Ethics approval and consent to participate}

All aspects of this study were approved by the Ethics Board of Zhongnan Hospital of Wuhan University.

\section{Author details}

'Department of Urology, Jingzhou Central Hospital, the Second Clinical Medical College, Yangtze University, Jingzhou 434020, China. ${ }^{2}$ Department of Urology, Zhongnan Hospital of Wuhan University, Center for Medical Science Research, Zhongnan Hospital of Wuhan University, Wuhan 430071, China. ${ }^{3}$ Department of Endodontics, Stomatology of Wuhan University, Wuhan 430079, China.

\section{Received: 17 December 2015 Accepted: 5 October 2016}

\section{Published online: 12 October 2016}

\section{References}

1. Ferlay J, Shin HR, Bray F, Forman D, Mathers C, Parkin DM. Estimates of worldwide burden of cancer in 2008: GLOBOCAN 2008. Int J Cancer. 2010; 127(12):2893-917.

2. McDermott DF. Immunotherapy of metastatic renal cell carcinoma. Cancer. 2009;115(10 Suppl):2298-305.

3. Escudier B, Eisen T, Stadler WM, Szczylik C, Oudard S, Siebels M, Negrier S, Chevreau C, Solska E, Desai AA, et al. Sorafenib in advanced clear-cell renalcell carcinoma. N Engl J Med. 2007;356(2):125-34.

4. Lang F, Foller M, Lang KS, Lang PA, Ritter M, Gulbins E, Vereninov A, Huber SM. Ion channels in cell proliferation and apoptotic cell death. J Membr Biol. 2005:205(3):147-57.

5. Caterina MJ, Schumacher MA, Tominaga M, Rosen TA, Levine JD, Julius D. The capsaicin receptor: a heat-activated ion channel in the pain pathway. Nature. 1997;389(6653):816-24.

6. Birder LA. TRPs in bladder diseases, Biochim Biophys Acta. 2007:1772(8):879-84.

7. Yang H, Wang Z, Capo-Aponte JE, Zhang F, Pan Z, Reinach PS. Epidermal growth factor receptor transactivation by the cannabinoid receptor (CB1) and transient receptor potential vanilloid 1 (TRPV1) induces differentia responses in corneal epithelial cells. Exp Eye Res. 2010;91(3):462-71.

8. Zhu Y, Xie C, Wang DH. TRPV1-mediated diuresis and natriuresis induced by hypertonic saline perfusion of the renal pelvis. Am J Nephrol. 2007;27(5):530-7.

9. Wang $\mathrm{Y}$, Wang $\mathrm{DH}$. Aggravated renal inflammatory responses in TRPV gene knockout mice subjected to DOCA-salt hypertension. Am J Physiol Renal Physiol. 2009;297(6):F1550-9.

10. Rayamajhi S, Contractor T, Wang DH. The potential of TRPV1 agonists for treating ischemia/reperfusion-induced renal injuries. Curr Opin Investig Drugs. 2009;10(9):963-70.
11. Surh YJ, Lee SS. Capsaicin in hot chili pepper: carcinogen, co-carcinogen or anticarcinogen? Food Chem Toxicol. 1996;34(3):313-6.

12. Minke B. TRP channels and Ca2+ signaling. Cell Calcium. 2006;40(3):261-75.

13. Meral O, Alpay M, Kismali G, Kosova F, Cakir DU, Pekcan M, Yigit S, Sel T. Capsaicin inhibits cell proliferation by cytochrome $\mathrm{c}$ release in gastric cancer cells. Tumour Biol. 2014:35(7):6485-92.

14. Sanchez AM, Martinez-Botas J, Malagarie-Cazenave S, Olea N, Vara D, Lasuncion MA, Diaz-Laviada I. Induction of the endoplasmic reticulum stress protein GADD153/CHOP by capsaicin in prostate PC-3 cells: a microarray study. Biochem Biophys Res Commun. 2008;372(4):785-91.

15. Lu HF, Chen YL, Yang JS, Yang YY, Liu JY, Hsu SC, Lai KC, Chung JG. Antitumor activity of capsaicin on human colon cancer cells in vitro and colo 205 tumor xenografts in vivo. J Agric Food Chem. 2010;58(24):12999-3005.

16. Anandakumar P, Kamaraj S, Jagan S, Ramakrishnan G, Asokkumar S, Naveenkumar C, Raghunandhakumar S, Devaki T. Capsaicin inhibits benzo(a)pyrene-induced lung carcinogenesis in an in vivo mouse model. Inflamm Res. 2012;61(11):1169-75.

17. Kilkenny C, Browne WJ, Cuthill IC, Emerson M, Altman DG. Improving bioscience research reporting: the ARRIVE guidelines for reporting animal research. Osteoarthritis Cartilage. 2012;20(4):256-60.

18. Kim SM, Oh EY, Lee JH, Nam D, Lee SG, Lee J, Kim SH, Shim BS, Ahn KS. Brassinin combined with capsaicin enhances apoptotic and anti-metastatic effects in PC-3 human prostate cancer cells. Phytother Res. 2015;29(11):1828-36.

19. Liu YP, Dong FX, Chai X, Zhu S, Zhang BL, Gao DS. Role of autophagy in capsaicin-induced Apoptosis in U251 glioma cells. Cell Mol Neurobiol. 2016; 36(5):737-43.

20. Sanchez AM, Sanchez MG, Malagarie-Cazenave S, Olea N, Diaz-Laviada I. Induction of apoptosis in prostate tumor PC-3 cells and inhibition of xenograft prostate tumor growth by the vanilloid capsaicin. Apoptosis. 2006:11(1):89-99.

21. Chow J, Norng M, Zhang J, Chai J. TRPV6 mediates capsaicin-induced apoptosis in gastric cancer cells-Mechanisms behind a possible new "hot" cancer treatment. Biochim Biophys Acta. 2007;1773(4):565-76.

22. Gunthorpe MJ, Szallasi A. Peripheral TRPV1 receptors as targets for drug development: new molecules and mechanisms. Curr Pharm Des. 2008; 14(1):32-41.

23. Prevarskaya N, Zhang L, Barritt G. TRP channels in cancer. Biochim Biophys Acta. 2007:1772(8):937-46.

24. Yang ZH, Wang XH, Wang HP, Hu LQ, Zheng XM, Li SW. Capsaicin mediates cell death in bladder cancer T24 cells through reactive oxygen species production and mitochondrial depolarization. Urology. 2010;75(3):735-41.

25. Chen D, Yang Z, Wang Y, Zhu G, Wang X. Capsaicin induces cycle arrest by inhibiting cyclin-dependent-kinase in bladder carcinoma cells. Int J Urol. 2012:19(7):662-8.

26. Lin JK, Liang YC, Lin-Shiau SY. Cancer chemoprevention by tea polyphenols through mitotic signal transduction blockade. Biochem Pharmacol. 1999; 58(6):911-5.

27. Kong AN, Yu R, Chen C, Mandlekar S, Primiano T. Signal transduction events elicited by natural products: role of MAPK and caspase pathways in homeostatic response and induction of apoptosis. Arch Pharm Res. 2000;23(1):1-16.

28. Kroemer G, Martin SJ. Caspase-independent cell death. Nat Med. 2005; 11(7):725-30.

29. Jung MY, Kang HJ, Moon A. Capsaicin-induced apoptosis in SK-Hep-1 hepatocarcinoma cells involves BCl-2 downregulation and caspase-3 activation. Cancer Lett. 2001:165(2):139-45.

30. Hail NJ, Lotan R. Examining the role of mitochondrial respiration in vanilloidinduced apoptosis. J Natl Cancer Inst. 2002;94(17):1281-92.

31. Kluck RM, Bossy-Wetzel E, Green DR, Newmeyer DD. The release of cytochrome c from mitochondria: a primary site for $\mathrm{BCl}-2$ regulation of apoptosis. Science. 1997:275(5303):1132-6.

32. Yang J, Liu X, Bhalla K, Kim CN, Ibrado AM, Cai J, Peng TI, Jones DP, Wang X Prevention of apoptosis by $\mathrm{BCl}-2$ : release of cytochrome $\mathrm{c}$ from mitochondria blocked. Science. 1997;275(5303):1129-32.

33. Fukamachi Y, Karasaki Y, Sugiura T, Itoh H, Abe T, Yamamura K, Higashi K. Zinc suppresses apoptosis of U937 cells induced by hydrogen peroxide through an increase of the Bcl-2/Bax ratio. Biochem Biophys Res Commun. 1998;246(2):364-9.

34. Lin L, Deng W, Tian Y, Chen W, Wang J, Fu L, Shi D, Zhao M, Luo W. Lasiodin inhibits proliferation of human nasopharyngeal carcinoma cells by simultaneous modulation of the Apaf-1/caspase, AKT/MAPK and COX-2/NF-kappaB signaling pathways. PLoS One. 2014;9(5):e97799. 
35. Huang HL, Hsieh MJ, Chien MH, Chen HY, Yang SF, Hsiao PC. Glabridin mediate caspases activation and induces apoptosis through JNK1/2 and p38 MAPK pathway in human promyelocytic leukemia cells. PLoS One. 2014;9(6):e98943.

36. Amantini C, Mosca M, Nabissi M, Lucciarini R, Caprodossi S, Arcella A, Giangaspero F, Santoni G. Capsaicin-induced apoptosis of glioma cells is mediated by TRPV1 vanilloid receptor and requires p38 MAPK activation. J Neurochem. 2007;102(3):977-90.

37. Sanchez AM, Malagarie-Cazenave S, Olea N, Vara D, Chiloeches A, DiazLaviada I. Apoptosis induced by capsaicin in prostate PC-3 cells involves ceramide accumulation, neutral sphingomyelinase, and JNK activation. Apoptosis. 2007;12(11):2013-24.

38. Park SY, Kim JY, Lee SM, Jun CH, Cho SB, Park CH, Joo YE, Kim HS, Choi SK, Rew JS. Capsaicin induces apoptosis and modulates MAPK signaling in human gastric cancer cells. Mol Med Rep. 2014;9(2):499-502.

Submit your next manuscript to BioMed Central and we will help you at every step:

- We accept pre-submission inquiries

- Our selector tool helps you to find the most relevant journal

- We provide round the clock customer support

- Convenient online submission

- Thorough peer review

- Inclusion in PubMed and all major indexing services

- Maximum visibility for your research

Submit your manuscript at www.biomedcentral.com/submit
C) Biomed Central 